\title{
A Comparative Study on Aqueous Chitosan Solution and Various Submucosal Injection Fluids Using a Three-Dimensional Sensor
}

\author{
Han Jo Jeon ${ }^{1}$, Seung Jeong ${ }^{2,3}$, Hyuk Soon Choi ${ }^{1}$, Se Hyun Jang ${ }^{1}$, Sang Hoon Kim¹, Seung Han Kim¹, \\ Jae Min Lee ${ }^{1}$, Eun Sun Kim", Bora Keum ${ }^{1}$, Yoon Tae Jeen ${ }^{1}$, Hong Sik Lee ${ }^{1}$, Hoon Jai Chun ${ }^{1}$, Jong Hoon Chung', \\ and Seong Nam Kim ${ }^{3}$ \\ ${ }^{1}$ Division of Gastroenterology and Hepatology, Department of Internal Medicine, Korea University College of Medicine, ${ }^{2}$ Department \\ of Biosystems \& Biomaterials Science and Engineering, Seoul National University College of Agriculture and Life Science, Seoul, and \\ ${ }^{3}$ Medical Engineering Research Center, The Standard Co. Ltd., Gunpo, Korea
}

\section{Article Info}

Received November 11, 2019

Revised February 5, 2020

Accepted February 8, 2020

Published online May 13, 2020

\section{Corresponding Author}

Hyuk Soon Choi

ORCID https://orcid.org/0000-0002-4343-6950

E-mail mdkorea@gmail.com

Han Jo Jeon and Seung Jeong contributed equally to this work as first authors.
Background/Aims: Chitosan, a natural polymer widely used in the biomaterials field, has been proposed as a potential submucosal injection solution. The purpose of this study was to compare the performance and efficacy of aqueous chitosan solution and commercialized submucosal injection fluids using a three-dimensional sensor and to evaluate the efficacy of the measured parameters.

Methods: Normal saline $(0.9 \% \mathrm{NaCl})$, as a control, Eleview ${ }^{\circledR}$ (Poloxamer 188$)$, Blue Eye ${ }^{\mathrm{TM}}(0.4 \%$ hyaluronic acid), and aqueous chitosan solution (2.0\%) were injected into the submucosa of porcine stomachs ex vivo. The mucosal elevation height, elevated surface area, and angle of the tangent of the submucosal fluid cushion were measured using a three-dimensional sensor. The rates of change for each variable were calculated, and the correlation between parameters was analyzed. Tissue specimens were stained with hematoxylin and eosin.

Results: All variables exhibited the highest values under chitosan injection. The mucosal elevation height rate of change differed significantly between normal saline and chitosan solution $(p=0.024)$. The elevated surface area rates of change for normal saline and Eleview ${ }^{\circledR}$ were significantly different from those for TS-905 and chitosan solution $(p=0.006$ and $p=0.009$, respectively). Further, height, area, and angle showed a positive correlation $(p<0.001)$. A histological examination revealed an even distribution of aqueous chitosan within the submucosa without tissue damage.

Conclusions: Aqueous chitosan was superior to normal saline and Eleview ${ }^{\circledR}$ and was noninferior to TS-905. A three-dimensional sensor and the measured parameters were effective and useful for evaluating the performance of submucosal fluids. (Gut Liver 2021;15:217-224)

Key Words: Endoscopy, gastrointestinal; Chitosan; Stomach; Injections; Imaging, three-dimensional

\section{INTRODUCTION}

Since the introduction of endoscopy for the diagnosis and treatment of gastrointestinal tract disease, therapeutic endoscopy has become a key tool for the removal of premalignant and malignant lesions. ${ }^{1}$ One of the most important techniques used during therapeutic endoscopy is the creation of a submucosal fluid cushion (SFC) via injection of a fluid into the submucosa, which elevates the mucosa of the lesion into a hemispherical shape. The SFC mechanically and thermally protects the muscularis propria and helps to prevent complications, such as thermal injury, bleeding, and perforation. ${ }^{2}$ At present, multiple submucosal injection fluids are available, and their advantages and disadvantages are widely contested.

Over the past 20 years, many studies have assessed the 
performance of various submucosal injection fluids. ${ }^{3-8}$ Among them, there are currently validated commercial products such as MucoUp ${ }^{\circledR}(0.4 \%$ hyaluronic acid) and Eleview $^{\circledR}$ (Polaxamer 188), which were approved by the Food and Drug Administration in 2015. Nevertheless, several shortcomings of the available submucosal injection fluids reiterate the need to find effective, safe, and costsaving submucosal solutions. Recently, several researchers have drawn attention to the potential of using photocrosslinkable chitosan $(\mathrm{PCH})$ as a submucosal fluid. ${ }^{9-12}$ Notably, chitosan, the main component of $\mathrm{PCH}$ and the second most abundant biopolymer in nature, is a polysaccharide copolymer of glucosamine and $\mathrm{N}$-acetyl glucosamine produced by the deacetylation of chitin. ${ }^{13}$ Chitosan is considered an innocuous substance, ${ }^{14}$ exerting hemostatic, ${ }^{15}$ antimicrobial, ${ }^{16}$ and antitumor effects, ${ }^{17}$ and has been shown to promote wound healing. ${ }^{18}$ Furthermore, chitosan itself is a highly viscous insoluble substance, which can be dissolved in an acidic solvent to form an aqueous solution. Given these advantageous properties, chitosan has been considered a strong candidate for use as a submucosal injection fluid. However, although current chitosan-associated research has focused on phase-change tests of $\mathrm{PCH}$ following exposure to ultraviolet (UV) radiation, there is a lack of data comparing chitosan with other solutions. In addition, $\mathrm{PCH}$ requires more preparation equipment and time before it can be applied to therapeutic endoscopy compared to the conventional method.

Therefore, we designed a simplified aqueous chitosan submucosal injection solution and hypothesized that it would create an elevated, convex SFC and would perform significantly better than clinically available submucosal injection fluids. Thus far, SFC studies have utilized rulers and photographic tools to assess the height of SFCs ex vivo, although three-dimensional (3D) sensors are already in use in the industrial and medical fields, especially in plastic surgery $^{19}$ and dentistry. ${ }^{20}$ Accordingly, the aim of this study was to evaluate the performance and efficacy of aqueous chitosan as a submucosal solution relative to conventionally used submucosal fluids. Additionally, we confirmed the efficiency of newly introduced parameters using a 3D sensor.

\section{MATERIALS AND METHODS}

\section{Ex vivo porcine stomach model}

The pigs used in the experiment were female hybrids with a bodyweight of $40 \mathrm{~kg}$. All animals were quarantined for one week prior to the start of the study and fasted the day before the experiment. The average temperature in the laboratory was $21.3^{\circ} \mathrm{C}$, and the humidity was $57.6 \%$. All experiments were approved by the Institutional Animal Care and Use Committee of Korea University and were
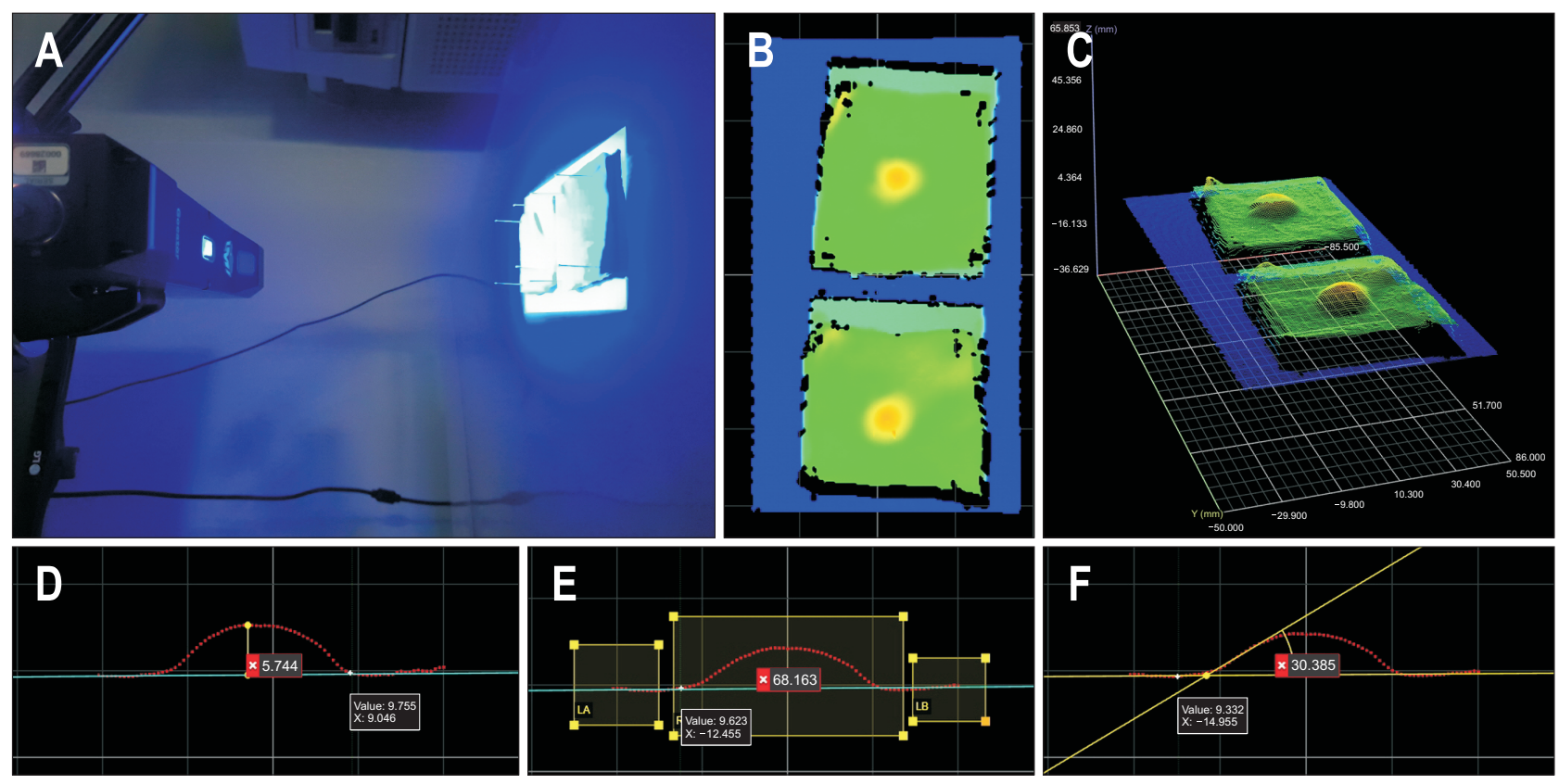

Fig. 1. Image of the three-dimensional (3D) scanner and cross-section of the submucosal fluid cushion based on the reconstructed 3D image. (A) A 2.5-mL syringe with a 23-gauge injection needle. From left to right, normal saline, Eleview ${ }^{\circledR}, \mathrm{TS}-905$, and aqueous chitosan solution, (B) 3D scanner acquiring data, (C) cross-section of the submucosal fluid cushion based on the reconstructed 3D image, (D) mucosal elevation height, (E) elevated surface area, and (F) angle of the tangent. 
performed under supervision in a licensed animal laboratory (IACUC approval number: KOREA-2018-0116).

\section{Specimens and injection method}

Pigs were sacrificed via intravenous injection of $\mathrm{KCl}(2$ $\mathrm{mmol} / \mathrm{kg}$ ), and the stomach was excised within 30 minutes after sacrifice. Only the stomach body was used, and the tissue was fixed on a $5 \times 5 \mathrm{~cm}$ cork plate with pins. One milliliter of each solution was injected tangentially (at a $45^{\circ}$ angle) into the stomach tissue using a $2.5 \mathrm{~mL}$ syringe with a 23 -gauge needle at a rate of $0.5 \mathrm{~mL} / \mathrm{s}$. The experiment was repeated eight times, and all injections were performed by the same individual.

\section{Injection solutions}

In total, four solutions were prepared for injection (Fig. 1A): normal saline (NS; JW Pharmaceutical Corporation, Seoul, Korea), a $0.9 \%$ solution of $\mathrm{NaCl}$; Eleview ${ }^{\circledR}$ (Aries Pharmaceuticals Inc., San Diego, CA, USA), a low-viscosity emulsion fluid containing poloxamer 188, polyoxyl15-hydroxystearate, medium-chain triglycerides, methylene blue, and sodium chloride in water; TS-905 (Blue Eye $^{\mathrm{TM}}$; The Standard Co. Ltd., Gunpo, Korea), a solution of $0.4 \%$ hyaluronic acid mixed with methylene blue; and a $2.0 \%$ aqueous chitosan solution (degree of deacetylation, 95\%; molecular weight, 20-100 kDa; Heppe Medical Chitosan $\mathrm{GmbH}$, Halle, Germany).

\section{Physicochemical properties of injection solutions}

The viscosity, injection pressure, and $\mathrm{pH}$ of the solutions used in the experiments were measured (Table 1). The viscosity was measured at $100 \mathrm{rpm}, 15 \mathrm{cP}$, and $25^{\circ} \mathrm{C}$ for 1 minute using an SC4-34 Spindle DV1 Viscometer (AMETEK Brookfield, Middleboro, MA, USA). The injection pressure was measured using a Push-Pull gauge, DS2200N (IMADA Inc., Northbrook, IL, USA), and a Tensile Strength Tester (test speed $100 \mathrm{~mm} / \mathrm{min}$ ) with an injection needle, NM-200U-0423 (Olympus, Tokyo, Japan) at $25^{\circ} \mathrm{C}$. $\mathrm{pH}$ was measured at $25^{\circ} \mathrm{C}$ using an Orion Star A215 (Thermo Fisher Scientific Inc., Waltham, MA, USA).

Table 1. Physicochemical Characteristics of the Solutions Used for Submucosal Injection

\begin{tabular}{lccc}
\hline \multicolumn{1}{c}{ Solution } & $\mathrm{pH}$ & Viscosity, cP & Injection pressure, N \\
\hline Normal saline $^{\text {N }}$ & 6.08 & 0.80 & 5.25 \\
Eleview $^{\circledR}$ & 6.00 & 5.60 & 15.74 \\
TS-905 $_{\text {Chitosan solution }}$ & 6.93 & 8.40 & 20.70 \\
\hline
\end{tabular}

\section{Three-dimensional sensor}

The 3D sensor, Gocator ${ }^{\circledR} 3110$ (LMI Technologies, Inc., Burnaby, BC, Canada), was mounted on a flat desk in an animal laboratory and connected to a computer. The 3D sensor scanned the SFC with high resolution at a speed of $5 \mathrm{~Hz}$, using a non-contact method (Fig. 1B). The images were captured every 5 minutes for 30 minutes and were analyzed using the Gocator Emulator, a stand-alone application. The captured two-dimensional image was converted into a 3D image to estimate the shape of the SFC (Fig. 1C).

\section{Study endpoints}

Our primary endpoint was the efficacy of aqueous chitosan solution in comparison with other solutions using a $3 \mathrm{D}$ sensor. Three variables were estimated by the $3 \mathrm{D}$ scanner directly; mucosal elevation height (MEH), the conventional parameter, elevated surface area (ESA), and angle of the tangent (AOT), which are newly introduced. MEH was defined as the vertical distance between the bottom plane of the tissue and the peak of the SFC (Fig. 1D). ESA was defined as the ESA from the bottom of the tissue of the SFC (Fig. 1E). AOT was defined as the angle between the tangent line and the bottom plane (Fig. 1F). Moreover, the rate of change for each parameter was calculated and compared to consider differences over time for efficacy assessment. The rate of change was defined as the amount of change over 30 minutes from the initial injection point for each parameter. Secondary endpoint was to assess additional parameters measured by the 3D sensor, namely ESA and AOT. Correlation analysis was conducted to define how similar the newly introduced variables, ESA and AOT, tend to be with the conventionally used MEH.

\section{Histopathology}

To compare the submucosal tissue injury induced by the SFC, the stomach tissue was fixed in $10 \%$ formalin solution. After the tissue was embedded in paraffin, it was sliced into $5 \mu \mathrm{m}$-thick sections, mounted on a slide, and stained with hematoxylin and eosin.

\section{Statistical analysis}

The nonparametric Kruskal-Wallis method was used to compare the results generated after the injection with each one of the four solutions. A mixed model for repeated measurement was used to confirm the difference in the pattern of changes between the solutions over time. Additionally, the Dwass, Steel, and Critchlow-Fligner method was used for post-hoc analysis. The correlation coefficients were determined between the three variables. All analyses were performed in SAS 9.4 (The SAS Institute, Cary, NC, USA). All p-values lower than 0.05 were considered significant. 


\section{RESULTS}

\section{MEH, ESA, and AOT change over time}

The plots of change over time for the MEH, ESA, and AOT are depicted in Fig. 2. Notably, the initial MEH, ESA, and AOT values were significantly higher for the chitosan solution, Eleview ${ }^{\circledR}$, and TS-905, than for NS (MEH, $\mathrm{p}<0.001$; ESA, $\mathrm{p}<0.001$; AOT, $\mathrm{p}<0.001)$. Further, the initial values of $\mathrm{MEH}$ and ESA were not significantly different between the chitosan solution, TS-905, and Eleview ${ }^{\circledR}$, while the initial AOT values were significantly higher for the chitosan solution than for Eleview ${ }^{\circledR}(p=0.040)$. However, as the experiment progressed, significant differences were observed between the solutions except for the NS. After 5 minutes, Eleview ${ }^{\circledR}$ began to differ significantly from the chitosan solution and TS-905 in terms of MEH (Eleview $^{\circledR}$ vs chitosan, $\mathrm{p}=0.002$; Eleview $^{\circledR}$ vs TS-905, $\left.\mathrm{p}=0.002\right)$,
ESA (Eleview ${ }^{\circledR}$ vs chitosan, $\mathrm{p}<0.001$; Eleview ${ }^{\circledR}$ vs TS-905, $\mathrm{p}<0.001$ ), and AOT (Eleview ${ }^{\circledR}$ vs TS-905, $\mathrm{p}=0.012$ ), and these differences were maintained for 25 minutes. During the experiments, there were no significant differences between the chitosan solution and TS-905 in terms of MEH, ESA, or AOT.

\section{Rate of change of MEH, AOT, and ESA}

To evaluate the performance of each submucosal fluid, the rates of change for each solution over the first $30 \mathrm{~min}$ utes after injection were also compared (Supplementary Table 1). According to our data, the rates of change of $\mathrm{MEH}$ and ESA were significantly different between solutions ( $\mathrm{MEH}, \mathrm{p}=0.008$; $\mathrm{ESA}, \mathrm{p}<0.001$ ), but the rate of change of AOT did not differ between treatments $(\mathrm{p}=0.073)$. Posthoc analyses were then performed to determine which solutions exhibited the highest efficiency (Fig. 3). Accord-
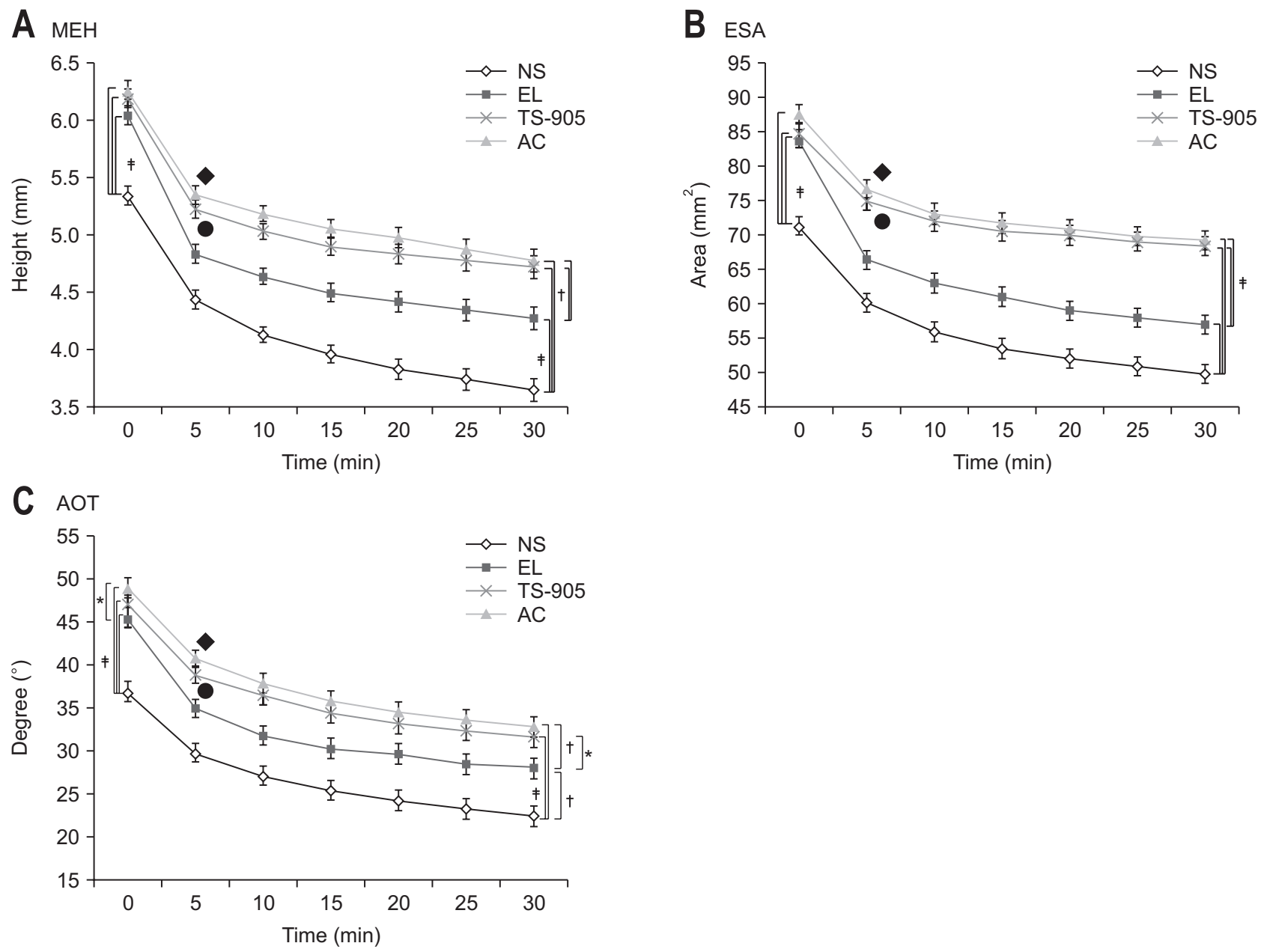

Fig. 2. Changes in variables over time. (A) Mucosal elevation height (MEH), (B) elevated surface area (ESA), and (C) angle of the tangent (AOT). Data were assessed for significance using a mixed model for repeated measurements. Symbol $\bullet$ : time required for a significant difference in the MEH to develop between Eleview ${ }^{\circledR}$ and aqueous chitosan solution; symbol $\bullet$ : time required for a significant difference in the MEH to develop between Eleview ${ }^{\circledR}$ and TS-905.

NS, normal saline; EL, Eleview ${ }^{\circledR}$; TS-905, hyaluronic acid; AC, aqueous chitosan. ${ }^{*} p<0.05,{ }^{\dagger} p<0.01,{ }^{\ddagger} p<0.001$. 

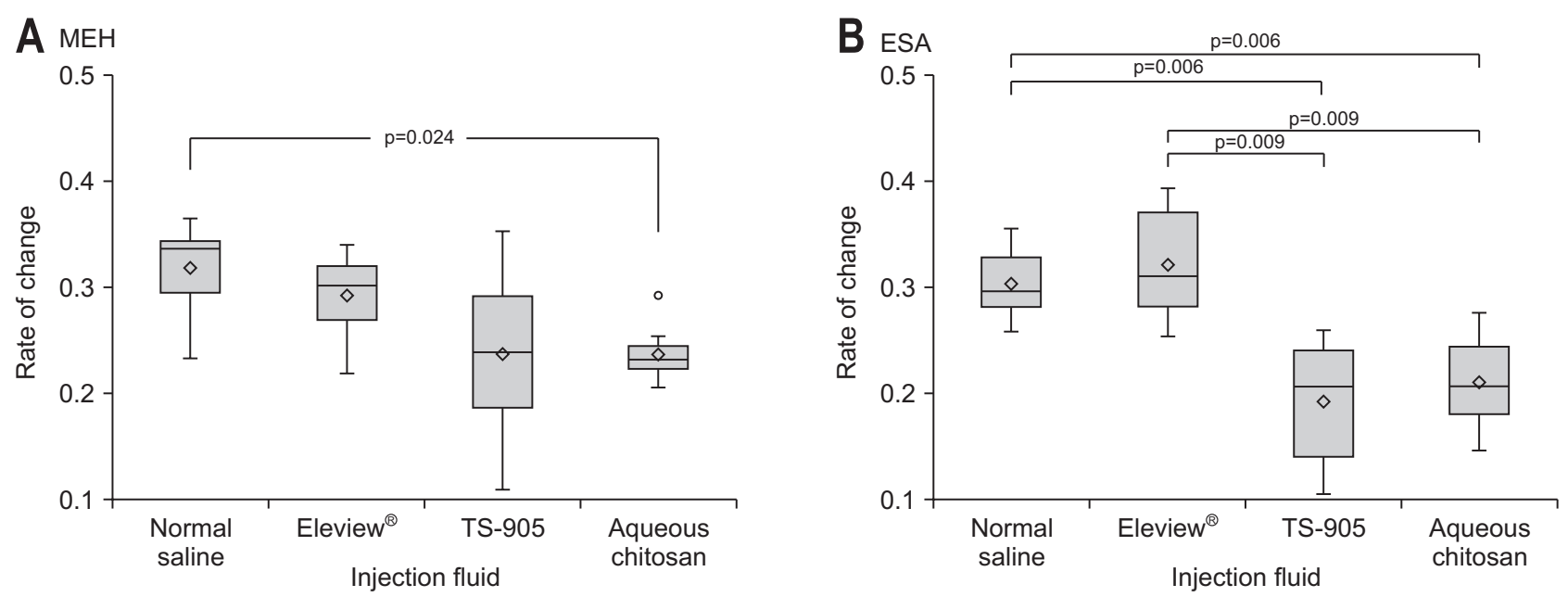

C АОт

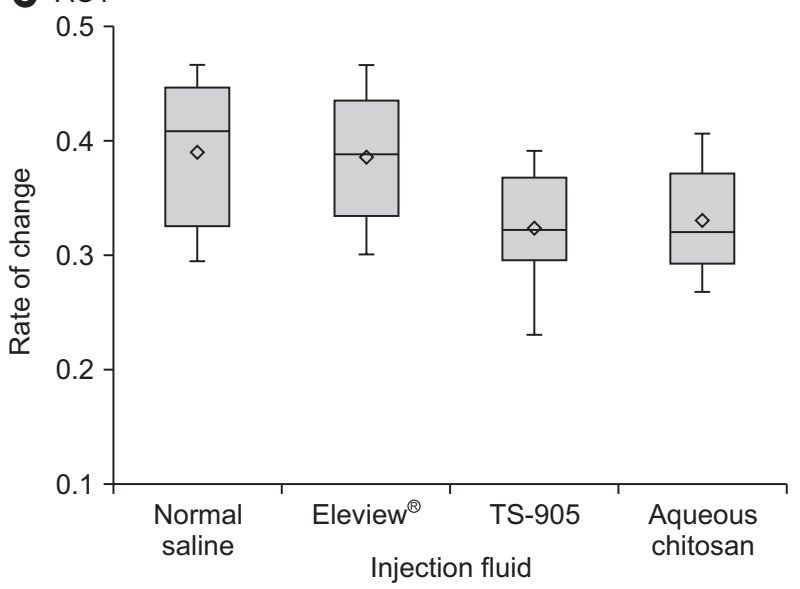

Fig. 3. Median rates of change in the four injection fluids. The boxplot shows the rate of change for each variable. Significant differences among individual solutions were assessed using the Dwass-Steel-Critchlow-Fligner method. (A) Mucosal elevation height (MEH), (B) elevated surface area (ESA), and (C) angle of the tangent (AOT). Symbol $\bigcirc$ : outlier; symbol $\diamond$ : mean value.

Table 2. Pearson Correlation Coefficient ( $\rho$ ) between Variables

\begin{tabular}{ccc}
\hline Variable & $\begin{array}{c}\text { Pearson correlation } \\
\text { coefficient } \rho\end{array}$ & p-value \\
\hline MEH-ESA & & \\
0 min & 0.804 & $<0.001$ \\
30 min & 0.927 & $<0.001$ \\
MEH-AOT & & \\
0 min & 0.809 & $<0.001$ \\
30 min & 0.885 & $<0.001$ \\
ESA-AOT & & \\
0 min & 0.838 & $<0.001$ \\
30 min & 0.900 & $<0.001$ \\
\hline
\end{tabular}

$\overline{M E H}$, mucosal elevation height; ESA, elevated surface area; AOT, angle of tangent.

ingly, the MEH rate of change was significantly different between NS and chitosan solution ( $\mathrm{p}=0.024)$, as was the ESA rate of change between NS and TS-905 $(\mathrm{p}=0.006)$ and NS and chitosan solution ( $\mathrm{p}=0.006)$. Furthermore, there were significant differences in the ESA rate of change be- tween Eleview ${ }^{\circledR}$ and TS-905 (p=0.009) and Eleview ${ }^{\circledR}$ and chitosan solution $(\mathrm{p}=0.009)$.

\section{Correlation between MEH, AOT, and ESA}

Potential associations between MEH, ESA and AOT were analyzed and confirmed. The Pearson correlation coefficients revealed statistical significance $(\mathrm{p}<0.001)$ at both 0 and 30 minutes after injection and demonstrated a strong positive correlation among the measured variables (Table 2).

\section{Histological evaluation}

Chitosan solution, TS-905, and Eleview ${ }^{\circledR}$, all exhibited an even distribution within the submucosa. Tissue sections of the SFC showed no muscle damage. At $\times 400$ magnification, the vessel appeared intact, and the mucosal and submucosal layers were separated from the margin, without damaging the surrounding tissue (Fig. 4). 

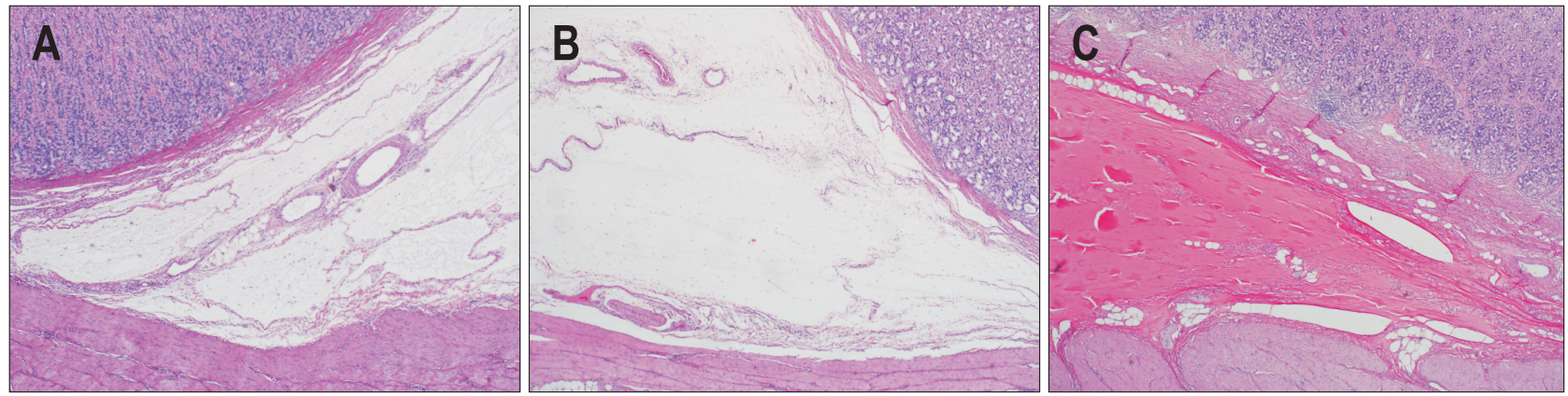

Fig. 4. Hematoxylin and eosin-stained sections of the marginal submucosal fluid cushion after solution injection ( $\times 400)$. Margins of the submucosal fluid cushion produced by (A) Eleview ${ }^{\circledR}$, (B) TS-905, and (C) aqueous chitosan solution.

\section{DISCUSSION}

Given the breadth of publications assessing and comparing the performance of submucosal injection fluids, several properties of these agents have been thoroughly described. First, the ideal submucosal fluid should be harmless, costeffective, easily injected using a needle and readily available in nature. ${ }^{21}$ Second, the viscosity of the submucosal fluid correlates with the duration of elevation. ${ }^{22}$ These requirements were, therefore, considered while evaluating the efficacy of aqueous chitosan as a submucosal injection fluid.

Various solutions have been assessed as submucosal fluids, including solutions of methylcellulose, ${ }^{3}$ hyaluronic acid, ${ }^{4}$ dextrose, ${ }^{5}$ glycerol, ${ }^{7}$ and hydroxyethyl starch. ${ }^{8,23}$ TS- 905 is a solution of $0.4 \%$ sodium hyaluronic acid certificated by European Communities recently for use as a submucosal solution. However, hyaluronic acid is relatively expensive ( $\$ 49.50-128.00$ per $\mathrm{mL})^{2}$ and has ability to promote tumor cell growth. ${ }^{24}$ Conversely, newly emerged Eleview $^{\circledR}$ contains mainly poloxamer 188 that has proved its effectiveness and safety for endoscopic mucosal resection and dissection..$^{25}$ Although its price $(\$ 8.10$ per $\mathrm{mL})$ is lower than that of hyaluronic acid, it has the disadvantages of inducing smoke formation and impairment of visualization during endoscopic submucosal dissection. ${ }^{26}$

$\mathrm{PCH}$ is made in the form of an Az-CH-LA aqueous solution by adding an azide group (Az) and lactose moieties to insoluble chitosan. This aqueous chitosan is crosslinked by UV radiation, resulting in the conversion of the liquid phase into a chitosan hydrogel. Although the utility of $\mathrm{PCH}$ as a submucosal fluid has been documented, several issues remain unaddressed. Importantly, conversion of the solution into a hydrogel requires time and UV irradiation, which causes tissue inflammation, while its safety remains doubtful. Additionally, homogeneous UV irradiation is difficult to achieve. ${ }^{10}$ Therefore, aqueous chitosan use was explored because of the limitations of PCH. Aqueous chitosan solution is a water-soluble polymer obtained through the neutralization of liquid chitosan, by mixing sodium hydroxide with acetic acid. Moreover, aqueous chitosan, unlike $\mathrm{PCH}$, does not require UV irradiation.

Through this study, interesting characteristics of $\mathrm{MEH}$, ESA, and AOT were discovered across the different submucosal fluids. From baseline, significant differences emerged between NS and the other solutions and were maintained for 30 minutes. Significant differences were noted between Eleview ${ }^{\circledR}$ and both chitosan and TS-905 within 5 minutes, but not between chitosan and TS-905 during the entire experimental period. Furthermore, TS905 and aqueous chitosan were the most viscous solutions, followed by Eleview ${ }^{\circledR}$ and NS. Therefore, aligning with viscosity studies, the solutions can be classified in terms of viscosity, i.e., high-viscosity, (chitosan, TS-905), lowviscosity $\left(\right.$ Eleview $^{\circledR}$ ), and solutions with little viscosity (NS). In this study, the injection pressure and viscosity were compared concurrently. As previously demonstrated, the higher the viscosity, the higher the injection pressure. ${ }^{27}$ Accordingly, chitosan and TS-905 had a similar injection pressure, greater than Eleview ${ }^{\circledR}$ (Table 1). Hence, it is likely that aqueous chitosan injection would be clinically convenient.

Interestingly, our study also revealed the time point at which the solutions began to differ. Specifically, the first 5 minutes were critical in determining the performance of the SFC. These differences may be attributed, in part, to the composition and state of the solution. Aqueous chitosan and TS-905 are natural polymer solutions, while Eleview $^{\circledR}$ is an emulsified aqueous solution.

$\mathrm{MEH}, \mathrm{ESA}$, and AOT were suitable for reflecting absolute values at time points and showing the trends of change over time, but they did not reflect the total decrement compared to the initial values during the observation period. Thus, the rates of change were devised in the performance assessment. According to these results, chitosan was the only solution to exhibit significant differences in the $\mathrm{MEH}$ and ESA rates of change relative to NS. Conversely, 
the $\mathrm{MEH}$ and ESA rates of change were not significantly different between Eleview ${ }^{\circledR}$ and NS or between TS-905 and chitosan, indicating that the SFC sinks faster with NS and Eleview ${ }^{\circledR}$ than with chitosan and hyaluronic acid during the first 30 minutes. There was no significant difference in the AOT rate of change, probably due to the lack of experimental tissues. We assume that a larger cohort would allow the generation of significant results. Further, the Pearson correlation coefficient indicated positive correlations between parameters. Hence, the result proves that the better performing SFC provides a higher and wider cushion with a larger angle, supporting the use of ESA and AOT as measures of SFC performance.

Prior to this study, only the MEH of the SFC had been measured to evaluate the performance of submucosal fluids, typically using a digital camera. ${ }^{22,26,28}$ However, these methods are less accurate and efficient than the 3D sensor described above. The 3D scanner performed real-time high-speed measurements by scanning with a blue lightemitting diode $(465 \mathrm{~nm})$ and reconstructed the 3D image of the SFC, producing a high-resolution cross-section. The processed data are characterized by high accuracy, consistency, repeatability, and reproducibility, with an error of less than $50 \mu \mathrm{m}$. Hence, 3D scanning technology is considered compatible with tests associated with submucosal fluids and could be incorporated into future studies.

This study has several limitations. It should be noted that we did not include hypertonic saline solution. We regarded safety as an important inclusion criterion for the selected solutions. However, hypertonic saline can cause tissue damage; therefore, it was excluded from our study. Nevertheless, even with the use of hypertonic saline solution, the results would not have changed due to the similar characteristics of NS and hypertonic saline solution. In addition, our ex vivo model provided limited simulation of the in vivo tissue tension and temperature, as it was resected and pinned to the plate.

In conclusion, we demonstrated the efficacy of aqueous chitosan solution as a possible submucosal product. $\mathrm{MEH}$, AOT, and ESA were measured using a 3D sensor to evaluate the SFCs. Liquid chitosan led to a higher, steeper, and larger SFC than the other solutions. Consequently, aqueous chitosan solution is superior to Eleview ${ }^{\circledR}$ and NS and performs comparably to sodium hyaluronic acid. Furthermore, the measured parameters positively correlated and proved the efficacy of the 3D scanner.

\section{CONFLICTS OF INTEREST}

S.J. and S.N.K. are employees of Standard Co., Ltd. No other potential conflict of interest relevant to this article was reported.

\section{ACKNOWLEDGEMENTS}

This work was supported by grants from the $\mathrm{Na}$ tional Research Foundation of Korea (NRF, No. 2017 R1C1B2006425) and Korea Technology and Information Promotion Agency for Small and Medium-sized Enterprises (No. S2588953). The funding sources were not involved in the study design, data collection and interpretation, or preparation of the final report.

\section{AUTHOR CONTRIBUTIONS}

Conceptualization: H.S.C., H.J.J., S.J., S.N.K., J.H.C. Data curation: H.J.J., S.J. Formal analysis: S.H.J., Sang Hoon Kim, Seung Han Kim, J.M.L., E.S.K. Funding acquisition: H.S.C., H.J.C. Methodology: H.S.C., B.K., H.J.J. Project administration: H.S.C., H.J.C. Visualization: H.J.J., H.S.C., Y.T.J., H.S.L., H.J.C. Writing - original draft: H.J.J. Writing - review \& editing: H.J.J., S.J., J.H.C., H.S.C., B.K., Y.T.J., H.S.L., H.J.C. Approval of final manuscript: all authors.

\section{ORCID}

Han Jo Jeon https://orcid.org/0000-0003-2258-1216 Seung Jeong https://orcid.org/0000-0001-9034-6061 Hyuk Soon Choi https://orcid.org/0000-0002-4343-6950 Se Hyun Jang https://orcid.org/0000-0001-8710-2007 Sang Hoon Kim https://orcid.org/0000-0003-3548-1986 Seung Han Kim https://orcid.org/0000-0001-9247-9175 Jae Min Lee https://orcid.org/0000-0001-9553-5101 Eun Sun Kim https://orcid.org/0000-0003-1820-459X Bora Keum https://orcid.org/0000-0003-0391-1945 Yoon Tae Jeen https://orcid.org/0000-0003-0220-3816 Hong Sik Lee https://orcid.org/0000-0001-9726-5416 Hoon Jai Chun https://orcid.org/0000-0002-5539-361X Jong Hoon Chung

https://orcid.org/0000-0003-0711-5655

Seong Nam Kim https://orcid.org/0000-0002-6895-7269

\section{REFERENCES}

1. Pasricha PJ. The future of therapeutic endoscopy. Clin Gastroenterol Hepatol 2004;2:286-289.

2. Uraoka T, Saito Y, Yamamoto K, Fujii T. Submucosal injec- 
tion solution for gastrointestinal tract endoscopic mucosal resection and endoscopic submucosal dissection. Drug Des Devel Ther 2009;2:131-138.

3. Feitoza AB, Gostout CJ, Burgart LJ, Burkert A, Herman LJ, Rajan E. Hydroxypropyl methylcellulose: a better submucosal fluid cushion for endoscopic mucosal resection. Gastrointest Endosc 2003;57:41-47.

4. Yamamoto $\mathrm{H}$, Yube T, Isoda N, et al. A novel method of endoscopic mucosal resection using sodium hyaluronate. Gastrointest Endosc 1999;50:251-256.

5. Katsinelos P, Kountouras J, Paroutoglou G, et al. A comparative study of $50 \%$ dextrose and normal saline solution on their ability to create submucosal fluid cushions for endoscopic resection of sessile rectosigmoid polyps. Gastrointest Endosc 2008;68:692-698.

6. Polymeros D, Kotsalidis G, Triantafyllou K, Karamanolis G, Panagiotides JG, Ladas SD. Comparative performance of novel solutions for submucosal injection in porcine stomachs: an ex vivo study. Dig Liver Dis 2010;42:226-229.

7. Uraoka T, Fujii T, Saito Y, et al. Effectiveness of glycerol as a submucosal injection for EMR. Gastrointest Endosc 2005;61:736-740.

8. Fasoulas K, Lazaraki G, Chatzimavroudis G, et al. Endoscopic mucosal resection of giant laterally spreading tumors with submucosal injection of hydroxyethyl starch: comparative study with normal saline solution. Surg Laparosc Endosc Percutan Tech 2012;22:272-278.

9. Ishizuka T, Ishihara M, Aiko S, et al. Experimental evaluation of photocrosslinkable chitosan hydrogel as injection solution for endoscopic resection. Endoscopy 2009;41:25-28.

10. Kumano I, Ishihara M, Nakamura S, et al. Endoscopic submucosal dissection for pig esophagus by using photocrosslinkable chitosan hydrogel as submucosal fluid cushion. Gastrointest Endosc 2012;75:841-848.

11. Hayashi T, Matsuyama T, Hanada K, et al. Usefulness of photocrosslinkable chitosan for endoscopic cancer treatment in alimentary tract. J Biomed Mater Res B Appl Biomater 2004;71:367-372.

12. Ishizuka $\mathrm{T}$, Hayashi $\mathrm{T}$, Ishihara $\mathrm{M}$, et al. Submucosal injection, for endoscopic mucosal resection, of photocrosslinkable chitosan hydrogel in DMEM/F12 medium. Endoscopy 2007;39:428-433.

13. Pillai CKS, Paul W, Sharma CP. Chitin and chitosan polymers: chemistry, solubility and fiber formation. Prog Polym Sci 2009;34:641-678.

14. Kean T, Thanou M. Biodegradation, biodistribution and toxicity of chitosan. Adv Drug Deliv Rev 2010;62:3-11.

15. Zhao X, Wu H, Guo B, Dong R, Qiu Y, Ma PX. Antibacterial anti-oxidant electroactive injectable hydrogel as self-healing wound dressing with hemostasis and adhesiveness for cutaneous wound healing. Biomaterials 2017;122:34-47.

16. Kong M, Chen XG, Xing K, Park HJ. Antimicrobial properties of chitosan and mode of action: a state of the art review. Int J Food Microbiol 2010;144:51-63.

17. Qin C, Du Y, Xiao L, Li Z, Gao X. Enzymic preparation of water-soluble chitosan and their antitumor activity. Int J Biol Macromol 2002;31:111-117.

18. Jayakumar R, Prabaharan M, Sudheesh Kumar PT, Nair SV, Tamura H. Biomaterials based on chitin and chitosan in wound dressing applications. Biotechnol Adv 2011;29:322-337.

19. Lübbers HT, Medinger L, Kruse A, Grätz KW, Matthews F. Precision and accuracy of the $3 \mathrm{dMD}$ photogrammetric system in craniomaxillofacial application. J Craniofac Surg 2010;21:763-767.

20. van der Meer WJ, Andriessen FS, Wismeijer D, Ren Y. Application of intra-oral dental scanners in the digital workflow of implantology. PLoS One 2012; 7:e43312.

21. Gostout CJ. Ode to the submucosal fluid cushion. Endoscopy 2004;36:638-639.

22. Hyun JJ, Chun HR, Chun HJ, et al. Comparison of the characteristics of submucosal injection solutions used in endoscopic mucosal resection. Scand J Gastroenterol 2006;41:488-492.

23. Fujishiro M, Yahagi N, Kashimura K, et al. Tissue damage of different submucosal injection solutions for EMR. Gastrointest Endosc 2005;62:933-942.

24. Matsui Y, Inomata M, Izumi K, Sonoda K, Shiraishi N, Kitano $S$. Hyaluronic acid stimulates tumor-cell proliferation at wound sites. Gastrointest Endosc 2004;60:539-543.

25. Spadaccini M, Hassan C, Maselli R, et al. Efficacy and safety of SIC-8000 $\left(\right.$ Eleview $\left.^{\circledR}\right)$ for submucosal injection for endoscopic mucosal resection and endoscopic submucosal dissection in an in vivo porcine model. Dig Liver Dis 2018;50:260-266.

26. Mehta N, Strong AT, Franco M, et al. Optimal injection solution for endoscopic submucosal dissection: a randomized controlled trial of Western solutions in a porcine model. Dig Endosc 2018;30:347-353.

27. Roth R, Akin M, Deligonul U, Kern MJ. Influence of radiographic contrast media viscosity to flow through coronary angiographic catheters. Cathet Cardiovasc Diagn 1991;22:290-294.

28. Fujishiro M, Yahagi N, Kashimura K, et al. Comparison of various submucosal injection solutions for maintaining mucosal elevation during endoscopic mucosal resection. Endoscopy 2004;36:579-583. 